\title{
Objectivity and Perspectival Content
}

\author{
Max Kölbel ${ }^{1,2}$ (D)
}

Received: 15 February 2019 / Accepted: 23 October 2019 / Published online: 31 December 2019

(c) The Author(s) 2019

\begin{abstract}
What is objectivity? What would it take to have objective representations and do we (humans) have what it takes? This paper aims to contribute to answering these questions. To this end, it isolates one relevant sense of objectivity and proposes a generalization of standard frameworks of representational content in order to engage with the question in a way that is rhetorically fair. Armed with a general conception of perspectival content, taken from the literature on centred or de se content, the paper articulates one necessary condition for objective representation: the possession of objective concepts and therefore objective contents. Two ways of meeting (or approximately meeting) this condition are discussed in an exploratory way.
\end{abstract}

\section{Introduction}

What is objectivity? What would it take to have objective representations and do we humans have what it takes? One obstacle to constructive debate of these questions is the fact that the mainstream theoretical framework for theorizing about representation already presupposes an answer, for it stipulates that the representational contents with which all representational states or acts are modelled are to be propositional contents that are objective in an important sense: if it is correct to believe such a content for anyone at any time, then it is correct to do so for everyone at all times. A rhetorically fair engagement with the question of whether human objective representation is possible (as well as actual and desirable) should look for a more neutral starting point on which it is a substantial question (rather than a matter of stipulation) whether there is objectivity. ${ }^{1}$

\footnotetext{
1 There is a more substantial point hiding behind the question of rhetorical fairness: if representation is by stipulation objective, this means that other types of mental state that are formed in response to a thinker's environment are portrayed as a different subject matter, so that the joint class of objective representations and non-objective responsive states of mind appears as disjunctive, not natural or not uniform. Thus, the terminology may lead us to ignore certain similarities or uniformities that hold across that class
}

Max Kölbel

max.kolbel@gmx.com

1 University of Vienna, Vienna, Austria

2 ICREA, Barcelona, Spain 
Those contemporary philosophers who believe in objectivity but simply take it for granted as part of their notion of representational content thereby treat the issue as one of choice of framework and therefore a pragmatic choice. Their attitude is thus similar to that of Richard Rorty, one of the best-known critics of objectivity. For Rorty has claimed that objectivity is nothing but an "ideology", i.e. that the possibility (actuality, desirability) of objectivity is not a matter that can be decided by rational argument, but is rather a question about the kind of narrative we want to adopt to make sense of our lives. ${ }^{2}$

In this paper I want to show how to escape this frame of mind, by offering a way of meaningfully and rationally discussing to what extent humans are capable of objective representation. The paper aims to identify one central sense of "objectivity" that figures in everyday as well as philosophical thinking, and to develop a framework for seriously examining whether, and to what extent, objective representation, in this sense of "objective", is possible.

After isolating the relevant sense of objectivity in Sect. 2, I will show that classic frameworks of representational content do not leave any room for non-objective representation, but that certain generalizations of these frameworks do not suffer from this problem: perspectival contents may be objective or not objective as the case may be (Sects. 3, 4). Armed with a conception of perspectival content, the paper then articulates one of the conditions that are required for objective representation: the possession of objective concepts and therefore the ability to form representations with objective contents (Sect. 5). The last section then explores two areas of thought in which human representations arguably achieve (approximate) objectivity (Sect. 6).

\section{Objectivity}

Defining objectivity is not straightforward: the term "objectivity" has been used to express many different ideas, often related, so I will have to begin by clarifying what I will mean by the term in this paper.

One sense of the term "objective" that is widespread and valuable makes objectivity an attribute of thinkers, i.e. an intellectual virtue (see e.g. Corcoran 1989; Gaukroger 2013). Thinkers are thought to be objective in an inquiry if they are not influenced by irrelevant factors, biases and especially their own idiosyncratic interests. Thus, on this reading, objectivity is a certain way of conducting an inquiry and collecting and evaluating evidence. A related sense of "objectivity" makes it an attribute of methods of enquiry: a method is objective in this sense, roughly, if it is

\footnotetext{
Footnote 1 (continued)

(see Kölbel 2018). The present point is to show that the question of objectivity can be tackled from a rhetorically neutral starting point if we adopt a perspectival contents framework of a kind well-known from several debates (on the de se, on centred contents, on unarticulated constituents, and on relativism and contextualism).

2 See e.g. Rorty (1985, p. 21, 1995, p. 42). See also Rorty (1987), where he develops the idea that science, viewed as objective, is a post-enlightenment surrogate for religion.
} 
free from bias (e.g. Belot 2017). While there is nothing at all wrong with this usage, it is not the sense of "objectivity" that I will be focussing on in this paper.

The sense I am interested in makes objectivity an attribute of subject matters, of topics of inquiry, or simply of questions. Thus, we often distinguish between objective matters, and matters of opinion (or subjective matters). Here is an example from Shapiro (2012, p. 213): the question who ran fastest in a particular race (e.g. $3000 \mathrm{~m}$ steeplechase) would seem to be objective, while the question who gave the better figure-skating performance would seem not to be objective in this way. Some further examples would be:

E1 "It is an objective matter whether the first human inhabitants of America came across the Bering Strait" 3

E2 "It is not an objective matter whether Alaska is worth a visit."

E3 "Many historians think that there is no objective historical truth."

E4 "Whether the water in that pool over there is cold is not an objective matter, but whether it is less than $20^{\circ} \mathrm{C}$ is."

E5 "It is an objective matter whether this piece of paper is a 20-Euro note."

E6 "Whether tipping 20 Euros is generous (on a given occasion), is not an objective matter."

These examples give at least a rough indication of the sense of "objective" I have in mind. ${ }^{4}$

It seems clear enough that in this sense one attributes objectivity to questions: "Who won?" or "Did this runner cross the line earlier than that runner?". Or perhaps to subject matters or topics (which in turn might be construed as made up of questions). However, I want to construe objectivity in the relevant sense as an attribute of potential contents of judgement, or of contents of representation in general (the next section will say more about how I conceive of representational contents). I regard this as a harmless stipulation that does not change the basic idea of attributing objectivity to questions, or even to questions of a certain type (topics, subject matters). Representational contents are very similar to yes-no questions: each content determines exactly one yes-no question. ${ }^{5}$ Moreover, wh-questions (like: "Who won?") can be thought of as being constituted by a series of yes-no questions (near enough).

By focussing on these examples and on objectivity as an attribute of contents of judgement, we have also excluded certain other uses of "objective", namely those that make objectivity either an attribute of facts (e.g. Nozick 2001, pp. 75-76), or construe objectivity as entailing truth (e.g. Burge 2010, p. 50). For I believe that

\footnotetext{
3 The example is from Boghossian (2007).

4 Accepting E1-E6 as examples of a widespread use of "objective" does not require accepting as true the claims made in them. For example, even those who want to disagree with E2 and claim that whether Alaska is worth a visit is an objective matter, perhaps as part of a wider objectivism about values, can still agree that E2 illustrates a typical use of the expression "objective". It is only this latter point that I am relying on.

5 Take a sentence $s$ that expresses a given content $p$. Then the unique corresponding question is "Is it the case that $s$ ?". Thanks to Paul Dekker for this suggestion.
} 
anyone using the sentence in E1 will take themselves to be committed to the objectivity of the content that the first human inhabitants of America came across the Bering Strait, no matter whether they did in fact come across the Bering Strait, i.e. independently of whether there is such a fact. I do not believe that this consequence of my stipulations should be troubling for anyone: we can always allow a separate sense of "objective" on which it applies to facts or to concrete representations, and on which it entails truth. For my purposes, it is important to isolate a sense of "objective" on which it does not entail truth or representational correctness. For the classifications exemplified in E1-E6 seem to be independent of any particular view of what the answer to the questions should be. It seems clear from these examples that in order to classify a question or content as objective one does not need to have any view on what the answer to the question is, or to believe or disbelieve the content.

Taking stock: I have ruled out the sense of "objective" on which it signifies an attribute of thinkers (an intellectual virtue), I have provided uses of "objective" that exemplify the sense I have in mind, and I have stipulated that objectivity is to be an attribute of representational contents, thereby regimenting the discussion of topics, subject matters or questions. Let me add some further comparative notes to clarify the sense of objectivity that I will be focussing on.

Nozick (2001, pp. 75-76) distinguishes three marks of the "ordinary" notion of objectivity $^{6}$ :

Accessibility:

When an objective content is true, this can be detected by different thinkers, or through different sense-modalities, or at different times or places.

Intersubjectivity:

There is or can be intersubjective agreement on objective contents.

Independence:

Objective contents represent aspects of a mind-independent reality, they are therefore true (or false) independently of anyone's "beliefs, desires, hopes, and observations or measurements".

I shall briefly explain why I believe that neither Accessibility nor Independence fits the use of "objective" exemplified above. Nozick himself observes (2001, pp. 91-92) that it is a consequence of Accessibility that it is not an objective matter which number Nozick is thinking about at a given moment (presumably when he is not telling anyone about it, and when he himself forgets about it subsequently). For there is (given our current means of detection) only one thinker and one modality by which this fact can be detected. Thus, according to Nozick, this is a "subjective fact". However, it seems that the notion of objectivity exemplified in E1-E4 allows us to classify contents as objective independently of whether anyone can ever detect them (consider especially E1). Independence, in Nozick's sense, does not fit the notion exemplified above either, as can be seen from example E5: whether a piece of

\footnotetext{
${ }^{6}$ I have transposed Nozick's claims about objective facts into my framework of objectivity as a feature of contents.
} 
paper is a 20-Euro note does depend on certain human beliefs, desires or attitudes. Nevertheless, the target notion plausibly classifies this as objective. Therefore Nozick's "ordinary notion" does not capture the notion exemplified above, and a fortiori the proposed explication of his "ordinary notion" as invariance under all (admissible) transformations does not help in the current enterprise.

Nozick's Intersubjectivity by itself does not help mark out what makes a given content objective in our target sense. As a necessary or sufficient condition, it is toothless. For it would seem that there is or can be intersubjective agreement on any representational content that two different subjects are capable of believing, i.e. to which they have access. On most conceptions of content, the same content is always accessible to different thinkers. Only certain unusual conceptions of content make room for contents that only one subject can believe, e.g. Frege's I-thoughts (Frege 1918) or similar egocentric contents (e.g. Pollock 1981; Stanley 2011, chs. 3-4). Intersubjectivity by itself therefore cannot explain any of the examples. Suppose we modify Intersubjectivity by deleting "or can be" in Nozick's characterization, thus saying that all and only those contents are objective on which there is actual intersubjective agreement. Then we still have not got a notion that fits our examples: whether anyone agrees with anyone else on the route by which the first humans came to America, or on whether Alaska is worth a visit does not decide the question whether E1 or E2 classify these contents correctly.

Similarly, Peacocke's "minimal objectivity" (2009) is not sufficient for objectivity as intended in my examples: a judgement is minimally objective just if making the judgement does not entail its correctness. Someone subscribing to E2 or E4 will presumably insist that one can nevertheless err in the matters there classified as nonobjective: clearly, one can erroneously believe that Alaska is worth a visit, just as one can erroneously believe the water to be cold. Such error need not be a matter of violating epistemic evidential or rational norms: one can be wrong on both scores even if one is fully justified. (So one can be wrong simply because Alaska/the water is not as it needs to be in order for the belief to be correct-do I need to spell out scenarios of disappointing trips to Alaska, unexpectedly warm thermal springs etc.?)

The characterization of objectivity I want to offer here also involves intersubjective agreement but in a way that contrasts with Nozick's. It also involves a different idea of independence. Finally, it involves Peacockian minimal objectivity as a necessary (but not sufficient) condition. My own approach is to say that if two thinkers both believe (or both disbelieve) the same objective content, then if one of them is right, the other one is also right. And if one of them is wrong, the other one is also wrong:

O1 A content is objective just if it is conceptually guaranteed that if it is correct (incorrect) for one thinker at one time to believe it, then it is correct (incorrect) to do so for any thinker at any time. ${ }^{7}$

\footnotetext{
7 To make explicit what the brackets are supposed to indicate: a content is objective just if: it is conceptually guaranteed that if it is correct for one thinker at one time to believe it, then it is correct to do so for any thinker at any time; and that if it is incorrect for one thinker at one time to believe it, then it is incorrect to do so for any thinker at any time.
} 
I believe that this characterization makes all our initial examples intelligible. Beliefs with contents that are objective in this sense purport to represent reality, or "what there is anyway", in Bernard Williams' sense: "the world as it is independently of the peculiarities of any observers" (1978, p. 241). ${ }^{8}$ At the same time O1 captures an epistemologically important kind: if one can identify someone who believes an objective content, and one believes they are likely to be right, then this gives one a reason to believe the same content. Objective contents therefore lend themselves naturally for pooling, transferring and storing information. ${ }^{9}$ A related idea can be found in Felix Mühlhölzer's proposed explication of the objectivity of a statement as "explicitness" with respect to all parameters on which truth depends (1988, pp. 187, 192).

An alternative, equivalent formulation would be this:

O2 A content is objective just if it is conceptually impossible for one thinker to believe it, another to disbelieve it, and neither of them to have made any mistake.

This version displays more transparently the resemblance of my notion of objectivity with Crispin Wright's notion of "Cognitive Command". ${ }^{10}$ Wright, however, thinks that Cognitive Command (i.e. being objective in the sense of O2) is part of the very idea of representation. On this point I depart from Wright: different devices might represent the same object of representation in mutually incompatible ${ }^{11}$ ways without there being any shortcoming or malfunction. This will be the case whenever the correctness of representing that object in that way depends also on who represents it or when, i.e. whenever the content of the representation is not objective. I do accept that Wright's Cognitive Command captures something like the essence of objective representation. This makes sense of examples E1-E6, and a representation that does not meet this requirement, while possibly still a representation, will count as non-objective.

In allowing non-objective representations, my conception agrees with that of Adrian Moore in his Points of View. However, while Moore allows non-objective, perspectival representations, he operates with a notion of content that makes

\footnotetext{
${ }^{8}$ Einheuser (2011) and Perry (2012, p. 222) also use very similar ideas of objectivity. However, O1 does not capture Thomas Nagel's notion of "objectivity" (1986, pp. 4-5), according to which objectivity is a matter of degree and the degree of objectivity increases with the number of subjective viewpoints represented or comprised. This notion is a development of a different aspect of Williams' account, namely the idea of an "absolute conception", see esp. Williams (1978, pp. 64-65).

${ }^{9}$ Even though, of course, some objective contents (such as Nozick's above-quoted example of the content to the effect that he thought of a certain number at a certain time) are not de facto believed by anyone, and no-one has evidential access to them. The claim here is merely that when an objective content is believed, then it lends itself to sharing etc.

${ }^{10}$ A discourse, on Wright's definition, exerts CC just if it is a priori that disagreements (except for those grounded in vagueness) involve a cognitive shortcoming (Wright 1992, pp. 92-93).

11 "Incompatible": ways of representing an object are mutually incompatible if one and the same thinker cannot rationally represent the object in both ways at once while being fully aware that it is the same object.
} 
contents objective by definition because they are the bearers of absolute truth-values (1997, e.g. pp. 4-5, 10). Thus, on Moore's account, a representation is perspectival if its content (in Moore's sense) depends on the representation's point of view (1997, p. 10). However, Moore does have a notion of "representation type", which corresponds roughly to my contents.

To conclude, I have suggested that $\mathrm{O} 1$ provides a good explication of the concept expressed by the term "objective" in occurrences like those in E1-E6. My decision to define "objective" in this way is partly stipulative, and reflects my interest in the concept defined. I do not mean to have argued that "objective" cannot legitimately be used in any other sense. However, I do mean to have argued that Nozick's "ordinary notion", Peacocke's “minimal objectivity" or Gaukroger's and Belot's objectivity understood as freedom from bias do not capture the notion exemplified in E1-E6. The main argumentative content of this paper will lie in what I am going to say in the next sections. ${ }^{12}$

\section{Perspectival Content}

Standard approaches to representational content stipulate that every content of representation is objective, for the standard notion of a representational content, i.e. a content of belief, assertion, etc., is that of a content that has an absolute truthvalue, a classic proposition. Whether contents are construed as structured propositions, or more simply as unstructured sets of possible worlds, ${ }^{13}$ it is standard to construe them as having absolute truth-values. This means that if we want to describe a given representation (for example a belief or disbelief) in terms of its content we will have to select its content from the set of classic contents, i.e. those with absolute truth-values. It means also that whenever two thinkers respectively believe and disbelieve the same content, at least one of them will be wrong: either the disbeliever has disbelieved something true, or else the believer has believed something false. ${ }^{14}$ Thus, our recently outlined notion of objectivity will not be very useful within a standard framework of representational contents: all these contents are objective by definition.

\footnotetext{
12 One further point of clarification: definition O1 defines what it is for a content to be objective in terms of the conditions under which it is correct to believe such a content. This does not mean that one could not bear attitudes other than belief towards objective contents (e.g. wondering, supposing, imagining, etc). Thanks to an anonymous referee for requesting this clarification.

13 I am throughout leaving open the issue whether such propositions or contents should be construed as structured propositions (as e.g. in King 2007; Soames 2010; Hanks 2011; Pickel 2019), or unstructured intensions (as e.g. in Stalnaker 1984, 2014; Chalmers 2002).

14 For simplicity, I am also assuming bivalence here. Strictly speaking, the idea of absolute truth-values leaves open how many truth-values there are, so that we could allow a third, indeterminate truth-value, without departing from the idea of absolute truth-values. If we allowed a third truth-value, possession of which made it correct to believe and also correct to disbelieve a content ("tolerance"), then such contents would achieve objectivity in the sense of $\mathrm{O} 1$ and non-objectivity in the sense of $\mathrm{O} 2$ (the two definitions come apart).
} 
A reluctance to depart from the classic framework of representational contents may lead some to reject $\mathrm{O} 1$, or to conclude that all contents are indeed objective. However, I argued that O1 captures our sample classifications E1-E6 well, and does so better than competitors. Moreover, those examples (E2, E4, E6) that deny objectivity seem to be examples of denying the objectivity of some bona fide representational contents (e.g. the content that Alaska is worth a visit or that the water is cold). There is no reason to think that those committed to the truth of these examples must ipso facto deny that the items whose objectivity is being denied are possible contents of representation. This motivates looking for alternatives to the classic framework. Contents are theoretical abstract entities that are appealed to by us in modelling various phenomena of representation, such as language and thought. So we are at liberty to select a conception of content that suits the phenomena we want to model-in our case a notion of perspectival content.

As anyone familiar with recent debates in the philosophy of language and mind will know, there are notions of content that have been developed for other purposes and that we can take more or less off the shelf for the current project. What we need is a conception of perspectival content, i.e. a conception that does not rule out by fiat that it could be correct for one thinker at one time to believe a given content, while it is not correct for another thinker or at another time. This condition is met by socalled "de se contents", "centred contents" or "relativized contents". 15

A good example is the notion of centred content developed in David Lewis's paper "Attitudes De Dicto and De Se" (1979). On this conception, each content is a function from "centred worlds" to truth values; or equivalently, a set of centred worlds (namely of those at which the value of the function is truth). A centred world is simply an ordered pair of a "centre" (or "location") and an ordinary possible world. A centre is itself an ordered pair of a thinker and a time. Thus, the evaluation points to which these functions assign truth-values are more fine-grained than they are in classic frameworks.

As Lewis points out, this model of representational content is a generalization of the classic conception of contents as functions from simple possible worlds to truthvalues (or equivalently sets of possible worlds). In the case of classic contents, the key idea is that it is correct for a thinker to believe a content just if the thinker's possible world, i.e. the actual world for that thinker, is one of the worlds in the set that is the content (when the function that is the content has the value truth for the thinker's world as argument). In the case of centred contents, the idea is that what is relevant

\footnotetext{
15 Castañeda (1967), Perry (1979) and Lewis (1979) are loci classici in the literature on de se content. See also Kölbel (2003), Egan (2007), Recanati (2007) and Feit (2008). For a summary with useful references, see Feit and Capone (2013). Cappelen and Dever (2013), Magidor (2015) have recently argued against the need to introduce special de se contents, they are answered by Ninan (2016), Torre (2018) and Morgan forthcoming. The extensive literature on relativism versus contextualism also discusses kinds of perspectival content, see e.g. Kölbel (2002, 2003), MacFarlane (2003, 2007), Lasersohn (2005), Egan et al. (2005), Stephenson (2007), Recanati (2007), Stojanovic (2007), Einheuser (2011), Cappelen and Hawthorne (2009), Dowell (2011), Zeman (2015), Dinges (2017) and Zakkou (2019). For overviews and references see the introduction to García-Carpintero and Kölbel (2008), MacFarlane (2012, 2014) and Kölbel (2015a, b).
} 
for evaluating the correctness of believing a given content is not only the thinker's possible world (which she shares with all her world mates, and which she inhabits at all times), but also who the thinker is, and at what time the thinking takes place, i.e. the thinker's location or "centre" in that world. In the centred content model, a belief $b$ is correct just if the centred world $\langle<s, t>, w\rangle$, where $s$ is the thinker having belief $b, t$ is the time at which $b$ occurs, and $w$ is the world in which $b$ occurs, is a member of $b$ 's content (or if $b$ 's content has the value true for that centred world as argument).

This is a generalization of the classic model, because some of these centred contents will be what I have called "objective" above ${ }^{16}$ : when thought of as functions with two arguments, a centre and a world, these functions will be constant with respect to the centre argument. Or, if we think of centred contents as sets of centred worlds: a content $c$ is boring/objective just in case for all centres $\langle s, t>$, whenever any centred world $\left.\left\langle<s^{*}, t^{*}\right\rangle, w\right\rangle$ is a member of $\left.c,\langle<s, t\rangle, w\right\rangle$ is also a member. In other words, whenever the content is true at a world and one centre, it is true at that world and any other centre. So, some of these centred contents have absolute truth-values in the sense that the content together with a possible world determines a truth value. Thus, contents with absolute truth-values are a special case in the framework of centred contents. Moreover, it is obvious that each of the contents in a classic framework of contents as sets of worlds (function from worlds to truth-values) has exactly one objective centred content as a counterpart that is true when believed at the same possible worlds. The centred content framework can therefore do what the classic framework can do, and much more (see Lewis 1979, p. 516).

Let me provide some simple examples of how these centred contents can be applied. Consider Hume on the 1st of January 1741: he believes himself to be Hume and to have written the Treatise. But consider also Heimson on the 1st of January 1979: deluded Heimson also believes himself to be Hume and to have written the Treatise. Then there are important similarities between Heimson and Hume that we may want to describe by attributing to them beliefs with the same contents.

Suppose we want to say that Hume and Heimson believe the same content in so far as each believes himself to be Hume; and that they also believe the same content in that each believes himself to be the author of the Treatise. In that case, no classic contents are suitable for these jobs. For Heimson's belief that he is Hume, as well as his belief to be the author of the Treatise, are false, while Hume's beliefs with these contents are true. Since both Hume and Heimson are inhabitants of the same world (they are actual), there is no such content available in the classic framework.

However, there are two suitable perspectival contents: there is the centred content c1 that contains all the centred worlds $\langle<s, t>, w\rangle$ such that $s$ is Hume, and there is another centred content $\mathrm{c} 2$ that contains all centred worlds $\langle<s, t>, w>$ such that thinker $s$ has written the Treatise at time $t$ at world $w$. The only person who can believe c1 correctly is Hume. By contrast, c2 can be believed correctly only by a thinker who has at the time and world of thinking written the Treatise. That's why, even though Hume and Heimson believe the same two contents, Hume's belief that

16 Or what Egan has called "boring" centred contents (2007). 
he is Hume is correct, while his belief that he has written the Treatise is correct as long as it occurs after 1740, when the Treatise was completed.

This introduction to the framework of centred contents is no doubt basic. ${ }^{17}$ There are several further applications with which the framework can be, and has been, motivated (predicates of personal taste, epistemic modals, unarticulated thought, etc.). ${ }^{18}$ However, I trust that centred contents and similar perspectival frameworks are sufficiently familiar to give readers some confidence that the idea of perspectival content is useful and not in itself incoherent.

One additional application where perspectival (or centred) content models are useful is precisely our current topic: objectivity. A framework of representational contents that leaves open whether the contents of any representations are objective, and which treats objectivity as a special case of representation in general, is better suited to examining what it takes to have objective representations, i.e. representations with objective contents. Those perspectival contents that are centre-independent, i.e. boring/objective, meet the definition of objectivity from Sect. 2: the correctness of believing these contents depends only on the possible world parameter, not on who believes it at what time.

It is important to address a possible misunderstanding of my proposal. ${ }^{19} \mathrm{I}$ have argued that we should admit a representational content that both Heimson and Hume believe: namely the centred content $\mathrm{c} 2$ that contains all those centred worlds $<<s$, $t>, w>$ such that $s$ has written the Treatise at $t$ in $w$. I claimed as an advantage of this proposal that we could say that Heimson and Hume believe the same content but that Heimson's belief is false, while Hume's is true, thus the content in question is a non-objective content in the sense of $\mathrm{O} 1$ above. Does this mean that is not an objective matter who wrote the Treatise, and a fortiori that it is not objective that Hume wrote the Treatise?-No. I do maintain that the question who wrote the Treatise has an objective answer, and in particular that it is an objective matter that Hume wrote it. Both Hume and Heimson correctly believe an objective perspectival content to the effect that Hume wrote the Treatise in 1740. However, there is a certain non-objective perspectival content, c2, that they also believe, and which can account for certain similarities between them. Hume does so correctly, while Heimson does so incorrectly. To put it a different way: when Hume believes himself to have written the Treatise, he believes several perspectival contents, some of them objective, i.e. centre-independent, some not. A question can be said to be objective

\footnotetext{
17 It has recently been called into question whether examples of so-called de se thought motivate the introduction of non-standard contents, e.g. by Cappelen and Dever (2013) and Magidor (2015). Nevertheless, I believe that the foregoing considerations do provide sufficient motivation given a certain assumption made above: namely that we want to model the similarities between Heimson and Hume by attributing beliefs with the same content. The main line of thought of the current paper provides additional motivation for perspectival contents. For recent responses to de se scepticism, see for example Ninan (2016), Torre (2018) and Morgan (forthcoming).

18 For an overview and references see the introduction to García-Carpintero and Kölbel (2008), MacFarlane $(2012,2014)$ and Kölbel (2015a, b).

19 Thanks to Daniel Morgan for alerting me to this possible misunderstanding.
} 
if there is an objective content that answers it, and a concrete belief state is an objective belief just if one of its contents is objective. More on this in the next section.

Before moving on, armed with the notion of perspectival content, let me very briefly mention two provisos. First, representational contents construed as functions from evaluation points (worlds or centred worlds) to truth-values (or as the corresponding sets) suffer from well-known problems. Notably, the problem of logical equivalents, namely that any two representations true at the same points are treated as having the same representational contents. Modelling representations in this way therefore has clear limitations, limitations that theorists have sometimes tried to overcome by introducing contents that are structured in some way (e.g. Carnap 1956; Lewis 1970; Barwise and Perry 1983; King 2007; Soames 2010; Hanks 2011; Pickel forthcoming). ${ }^{20}$ In my view, the problems discussed in this paper are independent of the question of how to deal with the problem of logical equivalents. In a framework of structured propositions there are also ways of dropping the assumption that contents have absolute truth-values. However, treating contents as intensions of some sort, i.e. as functions from evaluation points to truth-values, vastly simplifies the discussion. I am therefore adopting an unstructured framework for purposes of expository clarity and simplicity without prejudice regarding the question of whether contents must be structured. I will be assuming that perspectival contents are either identical to functions from centred worlds to truth-values, or at least determine such functions.

The second proviso regards the use of the notion of possible world in this characterization of perspectival contents. This notion seems already to presuppose that there is such a thing as an objective reality, namely the actual world. The framework presupposes that we can neatly divide our representations into those whose truthvalue is sensitive to the world only and those whose truth-value is in addition sensitive to a location or perspective within a world (a centre). Thus, the very framework seems already to presuppose not only the existence of an objective reality, i.e. the actual world, but also the possibility of objective representation.

The worry is important, especially in the current context. Our framework of theorizing should leave open whether there are objective representations and whether there is an objective reality. I see two ways to guarantee this.

The first would be simply to leave open what exactly possible worlds are, including even whether two causally interacting thinkers always "inhabit" the same world. This corresponds to Iris Einheuser's approach (2008, 2011). Worlds could simply be conceived of as whatever it is, in addition to the thinker and the time of thinking, that determines whether a given representation is correct. Further analysis might then reveal at a later stage what worlds must be in order to play this role.

The second way would be to avoid starting with ready-structured centred worlds as evaluation points, which already come with metaphysical assumptions about what worlds are. Instead we should start neutrally by introducing evaluation points only by their role, i.e. as something that evaluates contents. We could call them

\footnotetext{
${ }^{20}$ Others have tried to overcome the same difficulties without adding structure. See for example Stalnaker $(1984,2014)$ or Chalmers (2002).
} 
"perspectives" (as in Kölbel 2002) or "outlooks" (as in Coppock 2018). Still, some of the contents would be objective in the sense of $\mathrm{O} 1$ and $\mathrm{O} 2$ above. We could then re-introduce (objective) possible worlds simply as equivalence classes of perspectives (outlooks), namely classes of perspectives that coincide in their evaluations of all objective contents.

No doubt this issue deserves further attention. But for the moment, I shall be assuming the second way out. In other words, I shall assume that the primitives in our framework are thinkers, times and perspectives, as well as a possession relation between thinkers, times and perspectives. The notion of a possible world will be assumed to be derived in the way outlined. Thus, even when I speak of centred worlds, i.e. center-world pairs, as evaluation points, the notion of a world is here not a conceptual primitive, and it comes with no metaphysical baggage.

\section{The Significance of Assigning Contents}

We are now operating with perspectival contents, so the fact that we model a representation by assigning such a content no longer involves the prejudice that the representation is objective. As we saw in the case of Hume, the same belief state can involve believing several perspectival contents: non-objective $\mathrm{c} 2$ as well as an objective counterpart of it. What does it mean to attribute representational contents in this fine-grained sense? In part, this is a question about how assignment of representational content is constrained, i.e. what it predicts or explains. The main idea here is that the representational states of thinkers have certain independently detectable conditions of correctness, and that an assignment of representational content to a thinker at a time should reflect those conditions of correctness. But what exactly is it for a representation to have conditions of correctness, how are they manifested and what do they predict?

The general idea is that representations have a certain psychological and social role, which ultimately issues in behaviour. Let's start with the psychological role. Some combinations of representations are irrational, and this is reflected in incompatibilities of their contents. If two contents cannot, as a matter of their correctness conditions, be correctly believed by the same thinker at the same time, then the theory predicts that thinkers tend not to believe both at the same time, at least under favourable conditions. Similarly, thinkers will, under favourable conditions, and when sufficiently interested in the matter, believe contents the correctness of believing which follows from the correctness of other beliefs they already have. But in addition to these rational constraints, thinkers will also tend, under favourable circumstances, to believe only contents that it is correct for them to believe. In other words, mistakes must be explainable by pointing to ways in which conditions were not favourable (misleading evidence, the possession of other, incorrect beliefs, etc.). Relatedly, the methods regularly used in belief acquisition should be reflected in correctness conditions: if attributing a certain belief content would show the methods regularly used to be completely ineffective, then this is disconfirming evidence.

But there is also a certain social element in attributing belief contents. There are relations of deference amongst novices and mature thinkers, as well as amongst 
experts and lay people. The behaviour of experts and authoritative thinkers may be more significant for determining certain belief contents than that of others. Thus, in addition to a thinker's individual behavioural dispositions, there may also be social constraints on belief attribution. This is not the place to go into more detail. What is important for current purposes is that contents are shared amongst different members of a group or society, and that this sharing is the result of social interactions.

For concrete illustration, let us return to the example of Hume and Heimson. Each believes himself to have written the Treatise, so we can say that they believe the same content, $\mathrm{c} 2$, because in each case the condition for correctness is the same: the thinker needs to have written the Treatise at the time at which the belief occurs. Hume meets this condition from 1740 onwards, Heimson never meets it. The fact that the correctness condition is one that Hume meets (at certain times) and Heimson doesn't, shows that this content is not objective in the sense of $\mathrm{O} 1$.

However, Hume also believes the perspectival content, call it c3, which it is correct to believe for a thinker at a time at a world if and only if in that world Hume has written the Treatise by that time. Moreover, he believes the content, $\mathrm{c} 4$, that it is correct to believe for a thinker at a time and world iff at that world Hume has written the Treatise by $1 / 1 / 1741$ - a fully objective content the correctness of believing which depends solely on a possible world.

If Hume believes $\mathrm{c} 1$ and $\mathrm{c} 2$, he presumably also believes c3. If he also believes that day to be the $1 / 1 / 1741$ (i.e. he believes content c5: the set of centered worlds whose time is part of 1/1/1741), then he presumably also believes c4. Each of these beliefs has different conditions of correctness and thus a different content. Thus, Hume, on our assumptions, believes all of the following five centred contents:

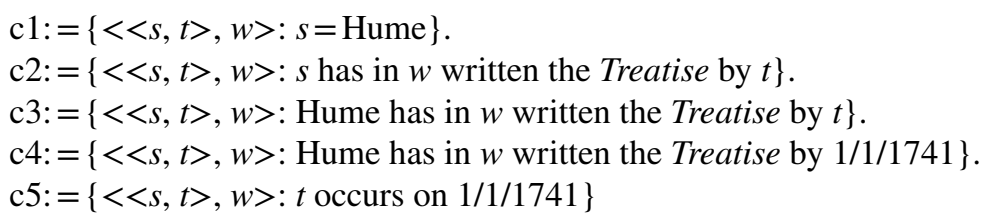

Had Hume not believed c5, perhaps he would not have believed c4. Had he suffered from amnesia and forgotten $\mathrm{c}$, perhaps he would not have believed c3 either. However, this would not have prevented him from believing c2. Or alternatively he might then have believed $\mathrm{c} 3$ and not $\mathrm{c} 2$. Clearly, thus, these contents can be accepted independently of one another. So distinguishing representations with such contents makes sense.

Similarly, we can ask whether Heimson believes c3-c5. Since he believes c1 and c2, he presumably also believes c3. Our current assumptions do not say anything yet about whether he believes c4 and c5: for all we have said, he may well be ignorant of c4. But looking up the publication date of the Treatise, would typically produce that belief. If he believed c5, then this would mean that he is not only deluded about who he is, but also about what day it is. But again, belief in c5 and belief in c3 will bring about belief in $\mathrm{c} 4$ also (at least if conditions are favourable).

It is the attribution of belief in $\mathrm{c} 2$ that explains why both Hume and Heimson experience a feeling of pride of authorship, or why both of them feel embarrassed 
when anyone points out an error in the Treatise. It also explains why Heimson's belief is correct, while Hume's is not. Belief in c3 or c4, by contrast, do not, by themselves, explain this pride or embarrassment. However, they can, by themselves, explain different behaviours: for example the tendency to praise or blame Hume for the merits or deficiencies of the Treatise.

In our case, Heimson and Hume each believe c1, c2 and c3. But none of these content attributions is superfluous, and in particular, we need c2 in order to explain pride and embarrassment patterns. It will not suffice to attribute to Hume belief in c4, and to Heimson belief in c6:

$$
\mathrm{c} 6:=\{\langle<s, t>, w>\text { : Heimson has in } w \text { written the Treatise by } 1 / 1 / 1979\} \text {. }
$$

For belief in c6 by itself does not explain Heimson's pride- and embarrassment-patterns, just as belief c4 by itself does not explain Hume's pride- and embarrassmentpatterns (Mere belief in $\mathrm{c} 4$, in the absence of belief in $\mathrm{c} 1$ and $\mathrm{c} 2$, does not predict or explain, e.g. shame when a mistake in the Treatise is pointed out).

In summary, the suggestion is that while it is correct to attribute to Hume in 1741 beliefs with all three contents $\mathrm{c} 2$, c3 or $\mathrm{c} 4$, there can also be situations where it is only correct to attribute to a thinker one of the three, but not the others. It will not be correct, for example, to attribute the objective content $\mathrm{c} 4$ to a thinker if that thinker's thought does not contain a repeatable thought-element that makes the thought about Hume, irrespective of who employs the element and when. Similarly, it will only be correct to attribute content $\mathrm{c} 2$ when the thought in question contains thoughtelements that makes the thought depend for its correctness on how things are with the thinker at the time of thinking.

\section{Objective Concepts}

What does it take, then, for a thinker to be able to have beliefs with objective contents? In general, the capacity for believing certain contents requires the possession of suitable concepts, just as believing c 2 requires possession of the first-person concept, while believing c3 and c4 requires possession of the concept of Hume. Objective contents, then, require the possession of objective concepts.

I cannot here offer a full-fledged theory of the sub-propositional elements of representational contents. However, in order not to be operating in a complete vacuum, I shall articulate some minimal desiderata on concepts and concept possession that would be part of a more complete theory of content composition.

I propose to think of concepts as abstract entities that are individuated, at least in part, by their conditions of correct application. Constituent concepts should contribute to explaining the constituted contents (and thereby correctness conditions) of representations, e.g. beliefs. If concepts are treated as at least determining functions 
from evaluation points (perspectives or centred worlds) to extensions, then it is plausible that they can perform this minimal role. ${ }^{21}$

We need to allow for the possibility (see Sect. 3 above) that it may be correct for one person to believe a content at one time, but not for another or at another time-the possibility of non-objective content. Therefore it makes sense to conceive of the conditions of correct application of a concept also in ways that may make the correctness of applying a concept in a given case depend on who applies the concept and when. To give an example, we will have to allow that there is a first-person concept $I$ which is governed by the rule of correct application that says that it is correct for a thinker to apply that concept only to him- or herself. Or perhaps a concept now that it is correct to apply only to the time at which it is being applied. Or, to move away from classic indexical concepts a little: we shall have to countenance a concept of pleasantness that is governed by the rule that says that it is correct for a thinker to apply it to an object only if the thinker has, at the time of application, a disposition to be pleased by that object (perhaps under certain normal conditions). Following the above idea that concepts determine functions from centred worlds to extensions, this will mean that some such functions vary with some arguments that differ only with respect to the centre of the centred world. ${ }^{22}$

How will such concepts and their application conditions contribute to the correctness conditions of complete representations? The rough idea is this: if a thinker believes that the smell of violets is pleasant, then her belief is correct just if she is, at the time of the belief, disposed to be pleased by the smell of violets. Similarly, when a thinker believes herself to be a philosopher then her belief is correct just if she is a philosopher at the time of believing. This is the correctness condition for believing a certain non-objective content, one that different thinkers might believe at different times with varying success in achieving correctness. Of course, typically someone who has a belief with that content will also have certain other beliefs with objective content, such as the belief that MK is a philosopher at noon on 23 October 2019but not always.

Concepts can be shared amongst a group of thinkers. A group of thinkers may all be using the same concept in the sense that they are all subject to the same rules of correct application. What does it mean to be subject to these rules? As mentioned above, this is a matter of participating in certain social activities. For example, the activity of learning the concept from other users, of correcting others, or being corrected, in the use of concepts, or issuing or receiving corresponding sanctions.

While concepts can be shared and have a social role, they also play a role in each individual thinker's psychology-hence the explanation of Heimson's pride by his belief that he wrote the Treatise. Concept possession involves the ability to form beliefs to the correctness conditions of which the concept has contributed. Finally, concept possession requires a minimum level of sensitivity to the conditions of

\footnotetext{
${ }^{21}$ For general expositions of such intensional systems in the context of formal semantics, see, for example, von Fintel and Heim (forthcoming) and Westerståhl (2012).

22 This possibility is ruled out by Stalnaker's recent adaptation of the centred worlds framework; see Stalnaker (2014, p. 118).
} 
correct application. What does sensitivity mean? It will not necessarily mean reliable conformity with these conditions, i.e. reliable correctness. However, it might involve reliable conformity under certain favourable conditions, i.e. a disposition non-accidentally to conform to the conditions of correct application under certain favourable conditions. ${ }^{23}$

It is this condition for concept possession that I want to focus on, now, in order to get a clearer idea on what might be required for the possession of objective concepts, and ultimately for the ability to have objective representations:

CP A thinker possesses a concept only if s/he has a non-accidental disposition to comply with the conditions of correct application of the concept under favourable conditions.

For the possession of objective concepts to be interesting, they need to be concepts that are shared with other thinkers (special case: the same thinker at a different time). Suppose an individual has at some time certain objective concepts and consequently can form beliefs with objective contents, but that this thinker at that time is the only thinker who has these objective concepts and can therefore form beliefs with these contents. Then the objectivity of these beliefs would lose much of its practical interest. So, if we are to find objective representation in any interesting sense there will need to be several thinkers (or at least the same thinker at different times) who possess a common pool of objective concepts which they can use to form beliefs with objective contents.

OR A group of thinkers (or the same thinker at different times) is capable of objective representation just if the members of the group (the persisting thinker) possess shared objective concepts which they can use for the formation of beliefs with objective contents.

OR now gives us a handle on the question of whether a group of thinkers is capable of objective representation. In the next section, I shall briefly explore two ways in which a group of thinkers may meet condition OR for objective representation. One way involves the possession of concepts that are naturally objective, and the other way involves concepts that are objective by design.

\section{Natural Objectivity and Objectivity by Design}

In this final section, I want to explore some ways in which the apparatus I have introduced may be used to argue that human societies do possess certain types of objective concepts and are therefore capable of forming representations with objective contents to which these objective concepts have contributed. The discussion will be

${ }^{23}$ See Kölbel (2016) for some elaboration. 
tentative but will, I hope, exemplify ways in which a substantive and fruitful discussion can be had about the question whether there is such a thing as objective representation.

Our requirement OR for objective representation requires that there be a group of thinkers who all share the same objective concept. The requirement of sensitivity for concept possession requires that any possessor of a concept have some disposition that ensures that under favourable conditions the thinker would apply the concept correctly (if she cares to apply it at all). How could social interaction amongst a group of thinkers produce such parallel dispositions? What sort of mechanism could explain such parallel dispositions?

An obvious place to look for an answer is amongst the cognitive abilities that are, as a matter of biology, shared amongst most human thinkers. The sense organs and human capacities for sense-perception would seem to offer an explanation of how humans can develop shared perceptual concepts.

If humans, by biological endowment, are affected in similar ways by certain perceptual features of their environment (shapes, colours, sounds, smells etc.), then they have a basis for joint possession of the following type of concept: concepts that it is correct to apply to an object just if the object has a disposition to cause a certain type of perceptual response in human observers under favourable conditions.

In the case of some perceptible features, this sort of account would seem too simplistic, because it may seem to require intersubjective comparisons of experiential responses. For example, let us say the concept of redness 1 is the concept that it is correct for a thinker to apply to an object iff the object has a disposition to cause redness qualia in human observers under favourable conditions. Now, if humans were already by nature endowed with the disposition reliably and selectively to respond with a certain type of experiential response (redness qualia) when faced with red surfaces under favourable conditions, then the human faculty that applies concepts—-let's call it the faculty of judgement—would simply need to interact reliably with that perceptual response. If the sensitivity to red surfaces is sufficiently similar in all humans (with colour vision), then the proposed dispositional concept of redness 1 could be possessed jointly by groups of human thinkers.

The model just offered for colour concepts is too simplistic for it presupposes that there is such a thing as redness qualia that are comparable across different individuals. Can we, non-circularly, explain the detection of redness by appeal to the occurrence of redness qualia in the detecting mind? I believe that this would be problematic if we thought that there was an intrinsic feature of the experience of different perceivers - the occurrence of redness qualia, i.e. if we thought that this feature was identifiable without reference to relations that thinker bears to other thinkers or objects. Perhaps future neuroscience will eventually identify an intrinsic experiential feature that can occur in different individuals, and which can play this role. However, it seems to me that there is no reason to expect this to happen. All we need for colour detection to work is that individuals have responses that are reliably correlated with exposure to red surfaces, and which are co-ordinated with other perceivers.

This suggests that we should revise the proposal for an objective concept of redness that might be shared by groups of humans: Redness 2 is the concept that 
it is correct for a thinker to apply to an object iff the object has a disposition reliably to cause (in favourable conditions) in each human perceiver a certain distinctive $^{24}$ response, namely the response that an actual typical ripe tomato would cause in that perceiver. ${ }^{25}$ Note that the reference to ripe tomatoes in the specification of the concept is non-essential. For the same conditions for correct application (hence the same concept) could be specified by pointing to a red object, or by mentioning any other red object, such as British pillar boxes, strawberries or Mickey Mouse's pants. $^{26}$

I believe that this sort of story is a blueprint for many naturally objective concepts shared by humans. Humans share by nature certain dispositions to respond to their environments, these shared dispositions enable groups of humans to be sensitive to, and thereby possess, the same objective concepts. ${ }^{27}$ Whenever the joint possession of objective concepts is based on such biological similarities amongst humans, I will speak of natural objectivity. There may of course also be areas of naturally objective thought that are not directly linked to sense perception.

For illustration, let me contrast a non-objective concept that can also be shared on the basis of our shared biological inheritance: the concept of pleasantness. As suggested above, this is the concept that it is correct for a thinker to apply to an object at a certain time if, and only if, that object is disposed, at that time, to please that thinker under favourable conditions. Here common possession of the concept is based on the common ability to experience pleasure in response to the environment. However, the concept is not objective because the range of correct application will vary from one thinker to another. Despite these individual variations, we can meaningfully identify the response of pleasure across different individuals on the basis of other, functional similarities. Further examples would be the concept of tastiness, that of being large/small, being tall/short, being warm/cold, being rough/smooth, being dark/light.

Which other perceptual concepts, besides colour concepts, might fulfil the job description of shared objective concepts? Many comparative concepts seem similarly to be supported by biologically shared perceptual capacities:
Shorter (longer) than
darker (lighter) than
warmer (colder) than

\footnotetext{
${ }^{24}$ Less distinctive for humans with red-green colour blindness.

25 If we want to call the distinctive response here mentioned a "redness quale", thus if we conceive of qualia as extrinsic and not intrinsic features, then qualia inversion (as envisaged in Shoemaker 1982) is conceptually impossible.

${ }^{26}$ Lewis (1997) criticizes attempts to define color terms non-circularly by (rigidified) reference to examples as "parochial", citing a mutual knowledge constraint on meaning. I would reject such a constraint. In any case, I have here not been speaking about linguistic meaning, but about concepts (though of course shared concepts). There is no space here to discuss the further problem of interpersonal variations in "pure color" perception-see e.g. Tye (2006), Gómez-Torrente (2016) and Hansen (2017).

27 I take Burge (2010) to be an attempt to analyse in much greater detail the causal dispositions I have here very abstractly called "dispositions to respond".
} 
smoother (rougher) than

louder (less loud) than

Of course, there are cases of comparison where our perceptual capacities differ in resolution, i.e. where some perceivers can discriminate, while others cannot. So, perhaps one perceiver will regard one sample of water as colder than another, while another will regard them as equally cold (one neither colder nor warmer than the other). It is a good question at what resolution we should set the concept that we say is shared amongst these concept users. I shall leave this problem aside.

These comparative concepts provide a straightforward opportunity for deliberately designing new concepts that are shared and objective: measurement concepts that rely on a previously understood dimension of comparison. Once we share objective concepts of longer/shorter than, we can introduce a standard of length, like a yardstick, or the standard metre designed between 1869 and 1875 by the International Metre Commission in Paris, and recently replaced. If we already have a shared concept of longer/shorter than, we can simply define the concept of being $1 \mathrm{~m}$ long as being neither shorter nor longer than the standard meter. This allows us to define further derived objective concepts, such as half as long or twice as long as $1 \mathrm{~m}$, and so on. ${ }^{28}$

Newly designed objective concepts do not always directly exploit our natural capacities for detecting the corresponding comparative difference. Thus, in the case of colder/warmer than, we do not set a standard sample (e.g. the coldness of some sample that stably retains its comparative coldness/warmth) and then use our ability for the detection of colder-warmer differences in order to tell whether a given object has the coldness of the sample. Designing our current temperature scales involved finding two sample points that could be reproduced, and they also involved creating instruments that exploit our detection of comparative length: thermometers. ${ }^{29}$ The length of the thermometer column measures the volume of the contained liquid. The volume of the liquid, in turn, is a measure of its temperature.

Length and temperature measurement are just two examples of how humans have developed technologies that allow them to share further objective concepts beyond those that are already supported by similarities in our natural cognitive capacities. This is what I call objectivity by design.

The basic measurements allow definitions of further derived measures, which inherit the objectivity of the basic measures. Thus, we have derived measures like the body-mass index (BME), the QALY (=quality-adjusted life year), or the rate of inflation. Sometimes, the purpose of these is to provide objective alternatives for

\footnotetext{
${ }^{28}$ The creation of a suitable standard for measuring length (or other quantities) that guarantees a maximum of objectivity (in the sense defined here), is not a trivial matter, but a substantial technological achievement. The Metre Commission was constituted by the best measurement experts of the time, yet they still took 6 years to create the standard metre bars. This was not due to lack of competence but owed to the practical difficulties of the task (see Quinn 2012).

${ }^{29}$ Chang (2004) gives a fascinating account of the arduous process by which reliable, objective temperature scales were developed.
} 
already existing, but less objective counterpart concepts-compare, for example the concept overweight and the concept having a BME greater than 25.

To conclude this section: objective representation, in the sense worked out in earlier sections, is possible for humans. It is made possible in part through our naturally evolved cognitive capacities and social interaction. However, humans also put a lot of effort into developing technologies of measurement, which vastly expand our ability to share objective concepts: objectivity by design. Finally, there are also derived concepts that have been deliberately introduced in order to achieve objectivity in areas where we previously had only non-objective concepts.

\section{Conclusion}

I have argued in Sect. 2 that objectivity in one important sense, exemplified by a number of examples, is the following property of representational contents: the property that a content has if and only if the correctness of believing the content is independent of who believes it and at what time $(\mathrm{O} 1, \mathrm{O} 2)$. I have shown in Sect. 3 that the classic notions of representational content rule out non-objective representation by fiat, and that notions of perspectival content, as they are known from the literatures on de se attitudes and on relativism, can serve as suitable alternatives that do not suffer from this problem. In Sect. 4, I outlined the theoretical role of perspectival contents, and in Sect. 5, I articulated one requirement for the capacity to have representations with objective contents: the possession of shared objective concepts. Finally, I argued in Sect. 6 that human societies seem to meet this requirement in two ways: they have concepts that are naturally objective, and concepts that are objective by design.

This shows at least one good way in which there can be rational argument about whether human societies are capable of objective representation. I have illustrated this by offering a sketch of an argument for a positive answer to the question. Objectivity by design, which relies on measurement technologies, depends on continuous maintenance and institutional support and therefore does not come for free. The fact that no-one seriously questions these expenses seems to be a clear sign of our confidence that we can achieve (approximate) objectivity, and of its obvious value. That objectivity in this sense is possible is not a mere stipulation, but an empirical fact. Nor is objectivity an ideology that in any way competes with human solidarity, as Rorty would have us believe.

Acknowledgements Open access funding provided by University of Vienna. This paper has descended from talks that were given on the following occasions: Philosophische Gesellschaft Zentralschweiz, Lucerne 2015; Padova Summer School in Philosophy on Objectivity, University of Padova 2016; PLMNetwork workshop on Subjectivity in Language and Thought University of Barcelona 2016; Brown Bag Talk, NYU Philosophy Department 2017, Department of Philosophy, University of Cologne 2018; Budapest Colloquium Talk, Central European University 2018. I thank the audiences for their valuable feedback, which, together with the comments from anonymous referees, has had a significant influence on the final shape of the paper. Research for this paper has been supported by the Spanish Ministry of Economy and Competitiveness, EXCELENCIA programme, Project No. FFI2016-80636-P, as well as the European Union's Horizon 2020 Research and Innovation programme under Grant Agreement No. 675415. 
Open Access This article is distributed under the terms of the Creative Commons Attribution 4.0 International License (http://creativecommons.org/licenses/by/4.0/), which permits unrestricted use, distribution, and reproduction in any medium, provided you give appropriate credit to the original author(s) and the source, provide a link to the Creative Commons license, and indicate if changes were made.

\section{References}

Barwise, J., \& Perry, J. (1983). Situations and attitudes. Cambridge, MA: MIT Press.

Belot, G. (2017). Objectivity and bias. Mind, 126, 655-695.

Boghossian, P. (2007). Fear of knowledge. Oxford: Oxford University Press.

Burge, T. (2010). Origins of objectivity. Oxford: Oxford University Press.

Cappelen, H., \& Dever, J. (2013). The inessential indexical: On the philosophical insignificance of perspective and the first person. Oxford: Oxford University Press.

Cappelen, H., \& Hawthorne, J. (2009). Relativism: A defence of monadic truth. Oxford: Oxford University Press.

Carnap, R. (1956). Meaning and necessity (2nd ed.). Chicago: University of Chicago Press.

Castañeda, H.-N. (1967). Omniscience and indexical reference. Journal of Philosophy, 64(7), 203-210.

Chalmers, D. (2002). On sense and intension. Philosophical Perspectives, 16, 135-182.

Chang, H. (2004). Inventing temperature: Measurement and scientific progress. New York: Oxford University Press.

Coppock, E. (2018). Outlook-based semantics. Linguistics and Philosophy, 41, 125-164.

Corcoran, J. (1989). The inseparability of logic and ethics. Free Inquiry, 9, 37-40.

Dinges, A. (2017). Relativism and assertion. Australasian Journal of Philosophy. https://doi. org/10.1080/00048402.2017.1284248.

Dowell, J. (2011). A flexibly contextualist account of epistemic modals. Philosophers' Imprint, 11(14), $1-25$.

Egan, A. (2007). Epistemic modals, relativism and assertion. Philosophical Studies, 133, 1-22.

Egan, A., Hawthorne, J., \& Weatherson, B. (2005). Epistemic modals in context. In G. Preyer \& G. Peter (Eds.), Contextualism in philosophy (pp. 131-170). Oxford: Oxford University Press.

Einheuser, I. (2008). Three forms of truth relativism. In M. Garcia-Carpintero \& M. Kölbel (Eds.), Relative truth (pp. 187-206). Oxford: Oxford University Press.

Einheuser, I. (2011). Relativized propositions and the Fregean orthodoxy. Philosophy and Phenomenological Research, 84, 590-603.

Feit, N. (2008). Belief about the self: A defence of the property view of content. Oxford: Oxford University Press.

Feit, N., \& Capone, A. (2013). The problem of de se attitudes. In N. Feit \& A. Capone (Eds.), Attitudes De Se: Linguistics, epistemology, metaphysics (pp. 1-25). Stanford: CSLI Publications.

Frege, G. (1918). Der Gedanke. Eine logische Untersuchung. Beiträge zur Philosophie des deutschen Idealismus, 1, 58-77. English translation as "The Thought: A Logical Inquiry", Mind 65 (1956), pp. 287-311.

García-Carpintero, M., \& Kölbel, M. (2008). Relative truth. Oxford: Oxford University Press.

Gaukroger, S. (2013). Objectivity: A very short introduction. Oxford: Oxford University Press.

Gómez-Torrente, M. (2016). Perceptual variation, color language, and reference fixing. An objectivist account. Noûs, 50, 3-40.

Hanks, P. (2011). Structured propositions as types. Mind, 120, 11-52.

Hansen, N. (2017). A new argument from interpersonal variation to subjectivism about color: A response to Gómez-Torrente. Noûs, 51, 421-428.

King, J. (2007). The nature and structure of content. Oxford: Oxford University Press.

Kölbel, M. (2002). Truth without objectivity. London: Routledge.

Kölbel, M. (2003). Faultless disagreement. Proceedings of the Aristotelian Society, 104, 53-73.

Kölbel, M. (2015a). Relativism 1: Representational content. Philosophy Compass, 10(1), 38-51.

Kölbel, M. (2015b). Relativism 2: Semantic content. Philosophy Compass, 10(1), 52-67.

Kölbel, M. (2016). Aesthetic judge-dependence and expertise. Inquiry, 59, 589-617.

Kölbel, M. (2018). Perspectival representation and fallacies in metaethics. Canadian Journal of Philosophy, 48, 379-404.

Lasersohn, P. (2005). Context dependence, disagreement, and predicates of personal taste. Linguistics and Philosophy, 28, 643-686. 
Lewis, D. (1970). General semantics. Synthese, 22, 18-67. Reprinted in David Lewis, Philosophical Papers vol. 1, Oxford: Oxford University Press, pp. 189-232.

Lewis, D. (1979). Attitudes De Dicto and De Se. Philosophical Review, 88, 513-43. Reprinted in David Lewis, Philosophical Papers vol. 1, Oxford: Oxford University Press, pp. 133-59.

Lewis, D. (1997). Naming the colours. Australasian Journal of Philosophy, 75, 325-42. Reprinted in David Lewis, Papers in Metaphysics and Epistemology, Cambridge: Cambridge University Press 1999, pp. 332-58.

MacFarlane, J. (2003). Future contingents and relative truth. Philosophical Quarterly, 53, 321-336.

MacFarlane, J. (2007). Relativism and disagreement. Philosophical Studies, 132, 17-31.

MacFarlane, J. (2012). Relativism. In D. G. Fara \& G. Russell (Eds.), The Routledge companion to the philosophy of language (pp. 132-142). London: Routledge.

MacFarlane, J. (2014). Assessment sensitivity: Relative truth and its applications. Oxford: Oxford University Press.

Magidor, O. (2015). The myth of the De Se. Philosophical Perspectives, 29, 249-283.

Moore, A. (1997). Points of view. Oxford: Oxford University Press.

Morgan, D. (forthcoming). Accidentally about me. Mind. Published online in Jan. 2019.

Mühlhölzer, F. (1988). On objectivity. Erkenntnis, 28, 185-230.

Nagel, T. (1986). The view from nowhere. Oxford: Oxford University Press.

Ninan, D. (2016). What is the problem of De Se attitudes. In M. García-Carpintero \& S. Torre (Eds.), About oneself: De Se thought and communication (pp. 86-120). Oxford: Oxford University Press.

Nozick, R. (2001). Invariances: The structure of the objective world. Cambridge, MA: Harvard University Press.

Peacocke, C. (2009). Objectivity. Mind, 118, 739-769.

Perry, J. (1979). The problem of the essential indexical. Nô̂s, 13, 3-21.

Perry, J. (2012). Reference and reflexivity (2nd ed.). Stanford: CSLI Publications.

Pickel, B. (2019). Structured propositions in a generative grammar. Mind, 128, 329-366.

Pollock, J. (1981). Language and thought. Princeton, NJ: Princeton University Press.

Quinn, T. (2012). From artefacts to atoms: The BIPM and the search for ultimate measurement standards. Oxford: Oxford University Press.

Recanati, F. (2007). Perspectival thought. Oxford: Oxford University Press.

Rorty, R. (1985). Solidarity or objectivity? In J. Rajchman, \& C. West (Eds.), Post-analytic philosophy (pp. 3-19). New York: Columbia University Press. Reprinted in Richard Rorty, Objectivity, Relativism and Truth, Cambridge: Cambridge University Press, pp. 21-34. (Page reference to reprinted version).

Rorty, R. (1987) Science as solidarity. In J. S. Nelson, A. Megill, \& D. N. McCloskey (Eds.), The rhetoric of the human sciences (pp. 38-52). Madison: University of Wisconsin Press. Reprinted in Richard Rorty, Objectivity, Relativism and Truth, Cambridge: Cambridge University Press, pp. 35-45.

Rorty, R. (1995). Is truth a goal of enquiry? Donald Davidson versus Crispin Wright. Philosophical Quarterly, 45, 281-300. Reprinted in Richard Rorty, Truth and Progress: Philosophical Papers, Vol. 3, Cambridge: Cambridge University Press (Page reference to reprinted version).

Shapiro, S. (2012). Objectivity, explanation, and cognitive shortfall. In A. Coliva (Ed.), Mind, meaning and knowledge: Themes from the philosophy of Crispin Wright (pp. 211-237). Oxford: Oxford University Press.

Shoemaker, S. (1982). The inverted spectrum. Journal of Philosophy, 79, 357-381.

Soames, S. (2010). What is meaning. Princeton: Princeton University Press.

Stalnaker, R. (1984). Inquiry. Cambridge, MA: MIT-Press.

Stalnaker, R. (2014). Context. Oxford: Oxford University Press.

Stanley, J. (2011). Know how. Oxford: Oxford University Press.

Stephenson, T. (2007). Judge dependence, epistemic modals, and predicates of personal taste. Linguistics and Philosophy, 30, 487-525.

Stojanovic, I. (2007). Talking about taste: Disagreement, implicit arguments, and relative truth. Linguistics and Philosophy, 30, 691-706.

Torre, S. (2018). In defense of De Se content. Philosophy and Phenomenological Research, 97, 172-189.

Tye, M. (2006). The puzzle of true blue. Analysis, 66, 173-178.

von Fintel, K., \& Heim, I. (forthcoming). Intensional semantics. Cambridge: MIT.

Westerståhl, D. (2012). Compositionality in Kaplan-style semantics. In E. Machery, W. Hinzen, \& M. Werning (Eds.), Oxford handbook of compositionality (pp. 192-219). Oxford: Oxford University Press.

Williams, B. (1978). Descartes: The project of pure enquiry. Harmondsworth: Penguin.

Wright, C. (1992). Truth and objectivity. Cambridge, MA: Harvard University Press. 
Zakkou, J. (2019). Denial and retraction: A challenge for theories of taste predicates. Synthese, 196, $1555-1573$.

Zeman, D. (2015). Relativism and bound predicates of personal taste. Dialectica, 69, 155-183.

Publisher's Note Springer Nature remains neutral with regard to jurisdictional claims in published maps and institutional affiliations. 